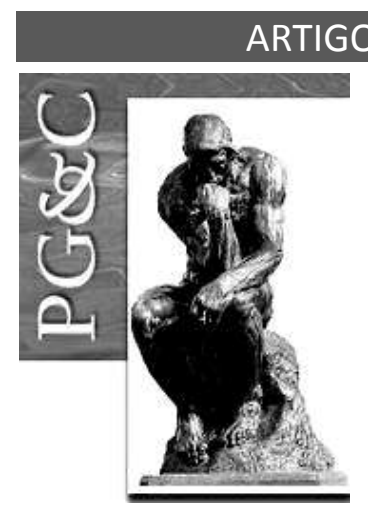

\title{
AS CONTRIBUIÇÕES DA GESTÃO DO CONHECIMENTO NOS PROCESSOS DE MEDIAÇÃO DA INFORMAÇÃO NO CONTEXTO DAS BIBLIOTECAS TÉCNICO-ACADÊMICAS
}

\author{
Carlos Henrique da Silva Sousa \\ Doutorando em Ciência da Informação pela Universidade Fernando Pessoa, \\ Portugal. Bibliotecário do Instituto Federal do Ceará, Brasil. \\ E-mail: chenrique@ifce.edu.br \\ Naira Michelle Alves Pereira \\ Mestra em Biblioteconomia pela Universidade Federal do Cariri, Brasil. \\ Bibliotecária do Instituto Federal do Sertão de Pernambuco, Brasil. \\ E-mail: nairamichelle ufc@yahoo.com.br \\ Felipe Ferreira da Silva \\ Mestre em Biblioteconomia pela Universidade Federal do Cariri, Brasil. \\ Bibliotecário da Universidade Federal do Ceará, Brasil. \\ E-mail: felipefs@ufc.br \\ Jonathas Luiz Carvalho Silva \\ Doutor em Ciência da Informação pela Universidade Federal da Bahia, \\ Brasil. Professor da Universidade Federal do Cariri, Brasil. \\ E-mail: jonathas.carvalho@ufca.edu.br
}

\begin{abstract}
Resumo
Este estudo objetiva demonstrar como a gestão do conhecimento pode contribuir nos processos de mediação da informação nas bibliotecas técnico-acadêmicas dos institutos federais, tornando-se uma ferramenta de fundamental apoio para os bibliotecários nos processos de mediação. Para o alcance do objetivo proposto, apresenta uma compacta revisão da gestão do conhecimento e da mediação da informação, buscando identificar e revelar os possíveis pontos de convergência desses processos, bem como seus benefícios e vantagens para essas bibliotecas. O estudo foi realizado por meio de pesquisa bibliográfica e se caracteriza como de natureza exploratório-descritiva. Como resultado, podemos observar que a gestão do conhecimento pode contribuir de modo expressivo nos processos de mediação da informação nas bibliotecas técnico-acadêmicas, de maneira implícita ou explícita, através da dinâmica de suas ações e práticas, elevando a qualidade de seus serviços e produtos, estimulando a inovação nesses ambientes.
\end{abstract}

Palavras-chave: Gestão do conhecimento. Mediação da informação. Bibliotecas técnico-acadêmicas.

\section{THE CONTRIBUTIONS OF KNOWLEDGE MANAGEMENT IN INFORMATION MEDIATION PROCESSES IN THE CONTEXT OF TECHNICAL-ACADEMIC LIBRARIES}

\begin{abstract}
This study aims to demonstrate how knowledge management can contribute to information mediation processes in the technical-academic libraries of federal institutes, becoming a fundamental support tool for librarians in mediation processes. To achieve the proposed objective, we present a compact review of knowledge management and information mediation, seeking to identify and reveal the possible points of convergence of these processes, as well as their benefits and advantages for these libraries. The study
\end{abstract}

Perspectivas em Gestão \& Conhecimento, João Pessoa, v. 10, n. 3, p. 3-18, set./dez. 2020. DOI: https://dx.doi.org/10.22478/ufpb.2236-417X.2020v10n3.55306

http://periodicos.ufpb.br/ojs2/index.php/pgc. ISSN: 2236-417X. Publicação sob Licença (cc) EY-NC-ND 
was carried out through bibliographic research and is characterized as exploratory-descriptive. As a result, we can see that knowledge management can contribute significantly to the processes of mediation of information in technical-academic libraries, either implicitly or explicitly, through the dynamics of their actions and practices, raising the quality of their services and products, stimulating innovation in these environments.

Keywords: Knowledge management. Information mediation. Technical-academic libraries.

\section{INTRODUÇÃO}

Os termos Gestão do Conhecimento (GC) e Mediação da Informação (MI) são relativamente novos quando trabalhados nas áreas da Biblioteconomia e Ciência da Informação $(\mathrm{B} \& \mathrm{Cl})$, com pesquisas sendo desenvolvidas, com bastante ênfase nessas temáticas, gerando debates e discussões tanto no âmbito acadêmico, quanto no profissional devido às promissoras perspectivas de desenvolvimento que ambas oferecem para o campo teórico e a práxis profissional. Essa última foi exatamente o que motivou a elaboração deste artigo.

No presente trabalho, a GC e a MI serão abordadas no contexto organizacional, mais precisamente em ambientes técnico-acadêmicos através do prisma de atuação de suas bibliotecas.

Nos tempos atuais, o conhecimento é considerado "chave" para o alcance de metas e objetivos por parte das organizações, como também para agregar valor aos serviços e produtos oferecidos por elas. Por essa razão que sua gestão e incorporação se faz necessária nos planos estratégicos como parte fundamental de qualquer planejamento organizacional. No âmbito do ensino, especificamente nas instituições de ensino superior (IES), é de suma importância uma abordagem baseada na GC para criação, compartilhamento, organização e uso do capital intelectual como prática integradora das ações cotidianas para o seu desenvolvimento e para a disseminação do conhecimento acumulado (MAIA, 2003).

Teixeira $(2015$, p. 17) ressalta que "o ambiente acadêmico é voltado para a geração e disseminação de conhecimentos e informação com seu caráter de transformação e inovação por meio do ensino, pesquisa e extensão". É caracterizado pela produção, comunicação e uso de conhecimentos e informação. Nesse sentido, a GC emerge como uma ferramenta capaz de agregar valor às iniciativas realizadas pelas bibliotecas técnico-acadêmicas (BTA's) através da dinâmica de suas ações. Considera-se que as BTA's são equiparadas às bibliotecas universitárias, ao considerar que seus objetivos estão fundamentados na missão, visão e valores da instituição de ensino, pesquisa e extensão à qual estão vinculadas.

O termo é relativamente novo na literatura da área e designa as bibliotecas pertencentes aos ambientes técnico-acadêmicos dos Institutos Federais de Educação, Ciência e Tecnologia do Brasil, atuando no suporte tanto ao ensino técnico, quanto ao superior, uma vez que estes oferecem cursos desde o ensino médio-técnico até a pós-graduação. (TEIXEIRA, 2015; SOUSA, 2017).

As ações das BTA's devem ser planejadas e executadas pelo bibliotecário por meio dos processos de $\mathrm{MI}$, de forma implícita e explícita, conforme veremos adiante.

É importante frisar que a mediação, segundo Almeida Júnior (2009, p. 92), "está presente em todos os fazeres do profissional da informação", incluídos nessa categoria os bibliotecários. E que de acordo com Silva (2015, p.105), "toda e qualquer mediação é um construto social e interacionista e envolve contextos coletivos e plurais..." sendo condição sine qua non identificar os atributos técnicos, pedagógicos e institucionais da mediação nos centros

Perspectivas em Gestão \& Conhecimento, João Pessoa, v. 10, n. 3, p. 3-18, set./dez. 2020. 
de informação, promovendo a prática da mediação como fenômeno de construção social e interacionista que pode estimular na construção de novos conhecimentos.

A partir do exposto, o presente estudo apresenta como condição problematizadora a seguinte pergunta: em que medida a gestão do conhecimento contribui para auxiliar nos processos de mediação da informação no contexto das bibliotecas técnico-acadêmicas? 0 objetivo deste estudo é demonstrar como a GC pode contribuir nos processos de MI nas BTA's dos institutos federais, a partir da identificação dos pontos de convergência entre elas, visando apontar seus benefícios, vantagens e desafios.

Os procedimentos metodológicos foram estabelecidos quanto aos fins como uma pesquisa de cunho exploratório e descritivo, pois se busca discutir sobre os pressupostos teórico-conceituais da GC e da MI no âmbito da Biblioteconomia e Ciência da Informação, fazendo ainda relações entre as práticas de GC e MI no contexto das BTA's. A base teórica se baseou na bibliografia especializada, pois se utilizou de leitura, análise e interpretação de conceitos e teorias sobre a GC e a MI. No âmbito da GC se destacam os autores: Ikujiro Nonaka, Hirotaka Takeuchi, Emeide Nóbrega Duarte, Marta Ligia Pomim Valentim, Thomas Davenport, Laurence Prusak entre outros. Enquanto que no âmbito da MI evidenciam-se os autores: Oswaldo de Almeida Júnior, Henriette Gomes e Jonathas Carvalho Silva.

\section{GESTÃO DO CONHECIMENTO NO CONTEXTO DA BIBLIOTECA TÉCNICO-ACADÊMICA}

A GC é um fenômeno complexo e multifacetado; uma prática que ganhou caráter universal nas últimas décadas devido à intensificação da globalização e é possível de ser aplicada em qualquer organização, pois objetiva trabalhar o conhecimento individual em conhecimento organizacional inserindo-o em seus produtos e serviços.

Para compreender melhor a GC é importante distinguir o que venha a ser dado, informação e conhecimento, pois não são raras as vezes em que eles são usados como sinônimos (SOUSA, 2017).

Deste modo, entendemos que dado é informação sem contexto, ou seja, registro referente a todo e qualquer evento, objeto ou pessoa, enquanto que informação são dados com sentido, significados e analisados dentro de um contexto. E conhecimento é a informação processada num contexto combinada a experiência individual e crenças. Nesse sentido, para Duarte et al. (2020), a informação e o conhecimento em uma perspectiva organizacional são insumos indispensáveis e são construídos juntos, pelas condutas de gestão ou práticas organizacionais.

Vistos esses conceitos, focaremos em algumas definições sobre GC evidenciadas na literatura antes de tratá-la no ambiente das bibliotecas das instituições de ensino superior, especificamente as dos institutos federais.

Nonaka e Takeuchi (2008) definem a GC como uma interação contínua e dinâmica entre o conhecimento tácito e o conhecimento explícito, num tipo de espiral do conhecimento organizacional. Para Davenport e Prusak (1998, p. 61), a GC é "o conjunto de atividades relacionadas à geração, codificação e transferência do conhecimento", baseia-se em aprimorar os recursos existentes na organização de maneira orientada para o conhecimento. Na visão de Duarte (2003, p. 283), a GC "consiste na integração de processos simultâneos desde a criação ao uso pleno do conhecimento viabilizado pela cultura de aprendizado e compartilhamento, no ambiente das organizações". Já Dalkir $(2011$, p. 3) afirma que a GC é como "uma coordenação deliberada e sistemática de pessoas de uma organização, tecnologia, processos e estrutura organizacional, a fim de agregar valor através da reutilização e da inovação". A Sociedade Brasileira de Gestão do Conhecimento (2013) define a GC como um processo sistemático, integrado e transdisciplinar que promove atividades para criação, identificação, organização, compartilhamento, utilização e proteção de conhecimentos estratégicos, gerando

Perspectivas em Gestão \& Conhecimento, João Pessoa, v. 10, n. 3, p. 3-18, set./dez. 2020. 
valor para as partes interessadas. Por sua vez, a International Federation of Library Associations (IFLA, 2019) definiu a GC como um processo de criação, armazenamento, compartilhamento e reutilização do conhecimento organizacional para capacitar uma organização a alcançar suas metas e objetivos.

Diante da multiplicidade de conceitos e abordagens sobre o tema, a GC é vista nesta pesquisa, em relação a seu termo, como maior que a soma de suas partes, permitindo a utilização de um conceito, sintetizado por Sousa (2009) em sua tese, que abrange diversas possibilidades de agregação de ideias, conseguindo, com isso, ser sustentáculo de vários modelos e referências. Assim, a conceituação a ser adotada neste estudo para a GC é

[...] a forma com que as organizações trabalham o conhecimento, englobando sua aquisição, seu compartilhamento, sua adaptação ao meio e seu aprimoramento, conforme o modelo adotado e os objetivos a alcançar, e o respeito aos preceitos da responsabilidade socioambiental, considerando, para isso, as fontes internas e externas, as explícitas e implícitas e o capital social existente (SOUSA, 2009, p. 49).

Deste modo, as organizações estarão aptas a utilizar o que alguns expoentes da GC consideram como o "bem" ou "recurso" mais valioso (SOUSA, 2009), como também incentivar a criação, o compartilhamento e o uso desse conhecimento através da existência de um ambiente favorável que permita o entrelaçamento da GC com os seus processos existentes.

Para tornar a gestão do conhecimento uma realidade para a organização, é fundamental compreender que o conhecimento gerado por cada sujeito organizacional necessita ser compartilhado aos demais membros, fator que depende de ações sistemáticas voltadas a isso. Assim, é necessário que a organização aja como gestora do conhecimento gerado internamente, de modo a beneficiar sua própria capacidade de atuação (SANTOS; VALENTIM, 2014, p. 25).

Assim sendo, as consideradas organizações do conhecimento baseiam "suas ações numa compreensão correta de seu ambiente e de suas necessidades, e são alavancadas pelas fontes de informação disponíveis e pela competência de seus membros" (CHOO, 2003, p.31).

Nesse contexto, emergem as Instituições de Ensino Superior (IES) descritas como os principais exemplos de organizações do conhecimento, que efetivamente dependem e prosperam no know-how coletivo e individual com seus colaboradores (McMANUS; LOUGHRIDGE, 2002). E que de acordo com esses autores, nestas instituições, uma abordagem baseada na GC para a criação, compartilhamento, organização e uso do capital intelectual deixa de ser mero discurso e passa a ser uma necessidade para uma prática integradora das ações cotidianas.

Nesse sentido, os Institutos Federais de Educação, Ciência e Tecnologia e suas BTA's destacam-se dentre essas organizações, por terem uma natureza compartilhadora e disseminadora do uso de suas informações, pois são organizações com base no conhecimento.

As BTA's são equiparadas às bibliotecas universitárias, pois, assim como essas, têm funções que estão pré-determinadas e condicionadas pelas funções da organização a qual pertencem devendo elas estabelecerem, promoverem, manterem e avaliarem uma gama de serviços de qualidade que suportem a missão e os objetivos da instituição (TEIXEIRA, 2015).

Valentim (2008, p. 7) nos diz que: "a informação considerada insumo para a construção de conhecimento necessita de ações específicas que deem conta de todas as atividades inerentes a esse processo de gestão, cujo impacto no ambiente organizacional é significativo para o desenvolvimento". Portanto, o sucesso dessas bibliotecas dependerá da

Perspectivas em Gestão \& Conhecimento, João Pessoa, v. 10, n. 3, p. 3-18, set./dez. 2020. 
habilidade de utilizar a informação e o conhecimento de sua equipe de colaboradores para melhorar as necessidades da comunidade técnico-acadêmica (MAPONYA, 2004; CASTRO, 2005).

Os bibliotecários gestores devem fazer uso de novos modos de gestão e de tecnologias, a fim de contemplar todas as necessidades informacionais da comunidade a que atendem. Assim, o bibliotecário atua nesse cenário de maneira mediadora entre as fontes disponibilizadas pelo ambiente de informação (biblioteca) e o usuário. Rostirolla (2006, p. 18) nos diz que: "Esta mediação requer ações e decisões do bibliotecário nos diferentes processos realizados na biblioteca, bem como o uso da tecnologia da informação para facilitar o processamento e transferência da informação ao usuário".

$\mathrm{Na}$ atuação dessas atividades, a biblioteca concentra em seus bibliotecários conhecimentos sobre as fontes de informação, os usuários, processos de tratamento da informação e estratégias de busca de informações em bases de dados, que nem sempre estão explicitados e que poderiam subsidiar a inovação, novos serviços, bem como a criação de novos conhecimentos (CASTRO, 2005).

A partir disso, vislumbra-se o potencial que a GC pode oferecer nos processos de mediação da informação nas bibliotecas técnico-acadêmicas. Antes, porém, veremos de que modo ocorre a mediação da informação no contexto das BTA's.

\section{MEDIAÇÃO DA INFORMAÇÃO NO CONTEXTO DA BIBLIOTECA TÉCNICO-ACADÊMICA}

A MI tem se configurado como um importante tema no cerne dos estudos e pesquisas na área da $\mathrm{B} \& \mathrm{Cl}$. Nessa perspectiva, os estudos sobre $\mathrm{MI}$ na $\mathrm{B} \& \mathrm{Cl}$, apresentam como pontos principais de investigação: as formas de mediação, comunicação e apropriação da informação em diversos contextos e atividades. Nesse processo, o profissional da informação apresenta-se como elo fundamentador na ação de interferência favorecendo a apropriação de informação que atenda plena ou parcialmente uma necessidade informacional, pois como afirma Almeida Júnior (2015, p. 25, grifo nosso) a mediação da informação se constitui de:

Toda ação de interferência - realizada em um processo, por um profissional da informação e na ambiência de equipamentos informacionais -, direta ou indireta; consciente ou inconsciente; singular ou plural; individual ou coletiva; visando a apropriação de informação que satisfaça, parcialmente e de maneira momentânea, uma necessidade informacional, gerando conflitos e novas necessidades informacionais.

Sobre isso Silva e Silva $(2012$, p.3) explica que a "mediação da informação inclui dois fatores fundamentais: a apropriação da informação que é inerente ao processo de produção/disseminação da informação e interferência que é inerente aos procedimentos de como a informação será destinada ao usuário".

Em outras palavras, Ferreira e Almeida Júnior (2013, grifo nosso) afirmam que o resultado fundamental do processo de $\mathrm{Ml}$ é o conhecimento, e para tanto, é imprescindível a atuação da figura do mediador, aquele que interfere no momento da busca por informação de outra pessoa.

Posto isto, pode-se observar que a MI envolve as atividades meio como planejamento, organização e representação da informação, e as atividades fim que são acesso, uso e apropriação da informação pelo usuário. Desse modo, compreender a MI fundamenta os pressupostos que dão vazão a três percepções: processos, fluxos e comportamentos informacionais, pois a mediação da informação será vital para entender como a informação é

Perspectivas em Gestão \& Conhecimento, João Pessoa, v. 10, n. 3, p. 3-18, set./dez. 2020. 
produzida, assim como os comportamentos informacionais envolvidos (SILVA; SILVA 2012, p.3).

Logo, refletir sobre mediação da informação implica percepcioná-la de três formas:

a) Primeiro, "para tratar de mediação, de início, é preciso situá-la como ação vinculada à vida, ao movimento, ao processo de construção de sentidos" (GOMES, 2010, p. 87);

b) Segundo, a mediação da informação possui seu processo de comunicação pautado na dialogia, que possibilita a interlocutores distintos o encontro e a manifestação das subjetividades que emanam da interlocução inter e intrassubjetiva, caracterizando-se como uma ação compartilhada e colaborativa, na qual o profissional da informação desempenha o papel de agente mediador, mas não representa o único agente desse processo de comunicação (GOMES, 2014).

c) Terceiro, "ao contrário da disseminação, a mediação não está restrita apenas às atividades relacionadas diretamente ao público atendido, mas em todas as ações do profissional da informação, em todo o fazer desse profissional" (ALMEIDA JÚNIOR, 2009, p. 6).

Nessa perspectiva, apresentamos a seguir as tipologias de MI implícita e explícita de Almeida Júnior (2009, p. 92-93); e técnicas pedagógica e institucional de Silva (2015):

Quadro 1 - Tipologias de mediação da informação

\begin{tabular}{|c|c|}
\hline \multicolumn{2}{|r|}{ MEDIAÇÃO IMPLÍTICA E EXPLÍCITA (ALMEIDA JÚNIOR, 2009) } \\
\hline TIPOLOGIAS & CARACTERÍSTICAS \\
\hline $\begin{array}{l}\text { Mediação } \\
\text { implícita }\end{array}$ & $\begin{array}{l}\text { Ocorre nos espaços dos equipamentos informacionais em que as ações são } \\
\text { desenvolvidas sem a presença física e imediata dos usuários. Nesses espaços, } \\
\text { como já observado, estão a seleção, o armazenamento e o processamento da } \\
\text { informação }\end{array}$ \\
\hline $\begin{array}{l}\text { Mediação } \\
\text { explícita }\end{array}$ & $\begin{array}{l}\text { Ocorre nos espaços em que a presença do usuário é inevitável, é condição sine } \\
\text { qua non para sua existência, mesmo que tal presença não seja física, como, por } \\
\text { exemplo, nos acessos a distância em que não é solicitada a interferência concreta } \\
\text { e presencial do profissional da informação. }\end{array}$ \\
\hline \multicolumn{2}{|r|}{ MEDIAÇÃO TÉCNICA, PEDAGÓGICA E INSTITUIONAL (SILVA, 2015) } \\
\hline TIPOLOGIAS & \begin{tabular}{|c|} 
CARACTERÍSTICAS \\
\end{tabular} \\
\hline $\begin{array}{l}\text { Mediação } \\
\text { técnica }\end{array}$ & $\begin{array}{l}\text { Concerne as ações de organização, representação da informação envidadas pelo } \\
\text { profissional da informação estimulando o uso da informação, seja em ambiente } \\
\text { físico ou virtual. Por exemplo, a elaboração de catálogos, interação por e-mail } \\
\text { e/ou redes sociais do acervo do centro de informação, entre outros. }\end{array}$ \\
\hline $\begin{array}{l}\text { Mediação } \\
\text { pedagógica }\end{array}$ & $\begin{array}{l}\text { Consiste na condução dos procedimentos e heurísticas a serem utilizadas no } \\
\text { processo de mediação. Para tanto, é fundamental um olhar constante nos estudos } \\
\text { de usuários contemplando questões relativas ao uso do acervo, das condições } \\
\text { tecnológicas, do serviço, das questões de pessoal e avaliação da atuação do } \\
\text { centro de informação de forma geral buscando uma aproximação com a } \\
\text { comunidade, assim como promovendo autonomia para que o usuário tenha } \\
\text { condições de escolha para apreensão e apropriação da informação }\end{array}$ \\
\hline $\begin{array}{l}\text { Mediação } \\
\text { institucional }\end{array}$ & $\begin{array}{l}\text { Está relacionada aos procedimentos de como o profissional da informação irá } \\
\text { buscar recursos (financeiros, pessoais, equipamentos, acervo, instrumentos } \\
\text { tecnológicos, etc.), seja dentro ou fora da instituição que o centro de informação } \\
\text { está inserido para concretizar suas ações e interferências, assim como promover } \\
\text { sua sustentabilidade. }\end{array}$ \\
\hline
\end{tabular}

Fonte: Almeida Júnior (2009) e Silva (2015)

Desse modo, compreende-se que "a mediação da informação age como um fio condutor que liga processos e aproxima construtos de processamentos técnicos aos procedimentos de ação social e pedagógica" (SILVA; SILVA 2012, p. 4).

Perspectivas em Gestão \& Conhecimento, João Pessoa, v. 10, n. 3, p. 3-18, set./dez. 2020. 
Outrossim, Almeida Júnior afirma que a Ml é um processo histórico-social, portanto, a ideia de neutralidade é totalmente descontextualizada desse conceito pois a atividade de mediar não está dissociada do tempo, espaço e do entorno e contexto social, político, cultura e econômico dos sujeitos envolvidos.

Nesse sentido, Bicheri (2008, p. 93) reitera a concepção de Almeida Júnior sobre MI quando diz que, mediação envolve a ação de quem intercede, interfere por algo e por alguém; implicando em diversos caminhos, opções e escolhas. Constatamos que na mediação alguém está entre duas ou mais pessoas/coisas, facilita uma relação, serve de intermediário, sugere algo, sem agir pela pessoa ou lhe impor alguma coisa.

Sobre isso, Gomes (2014) lembra a importância do desenvolvimento da consciência e competência do mediador, para realização da interferência sem manipulações, de forma a garantir o acolhimento, a escuta, a observação e o diálogo com os envolvidos na ação, o direito de acesso a diversidade de ideias e a liberdade de pensamento, inibindo a censura e o preconceito. A ação de mediar é pensar no protagonismo do usuário, isto é, o conceito de mediação da informação, nos alerta sobre a necessidade de uma consciência que perceba o usuário como sujeito ativo do processo de apropriação de informação.

Dessa maneira, ela (MI), torna-se instrumento transformador no processo de apropriação da informação quando nos permite deixar de lado a concepção de que o usuário é passivo e mero receptor de informações, permitindo olhar para o mesmo como quem determina ou não a existência da informação. A autoria deixa de ser única e passa a ser repartida, distribuída entre todos os que farão uso da informação em potência (ALMEIDA JÚNIOR, 2009).

Em outras palavras, é possível observar que as tipologias de mediação de Almeida Júnior (2009) e Silva (20015) expressam o processo de mediação da informação a partir de uma visão holística do fazer bibliotecário, tendo como proposta a construção de estratégias de aprendizagem por meio da informação a partir do protagonismo dos sujeitos no processo de acesso, uso, apreensão e apropriação da informação.

De acordo com Gomes (2014) compreender a mediação nessa perspectiva, revela seu processo dialético, exigindo daquele que atua como mediador a sensibilidade para atuar de forma respeitosa essa condição fundante da ação mediadora, reconhecendo que a partir de cada prática é necessário se autoavaliar na busca do seu autoconhecimento e superação dos seus próprios limites, entendendo que é também um sujeito implicado no processo, que se responsabiliza por ele, aperfeiçoando seu próprio perfil protagonista.

Por tudo isso, percebe-se que a MI constitui-se em um processo de aprendizagem necessário ao desenvolvimento de competências e habilidades específicas para apreensão e apropriação da informação por parte dos usuários. Além disso, pode-se afirmar que a MI cultiva e estimula o usuário a desenvolver seus conhecimentos ao longo de suas necessidades informacionais, em um processo de aprender a aprender. Entende-se aqui que esse processo de aprendizagem é crucial na sociedade atual, submetida a rápidas e profundas transformações em virtude da grande produção de conhecimentos científicos e tecnológicos.

Para Pieruccini (2007), as bibliotecas são dispositivos de transmissão e comunicação, pois se utilizam de meios técnicos, linguagens e formas de interação com intencionalidades, ao visarem à relação entre sujeito e realidade e, portanto, não podem ser compreendidas como meros suportes de informação. Isso porque, sua configuração física, seus recursos, formas e práticas interferem no seu discurso, na sua estrutura e nos modos de interação entre os sujeitos que lá atuam em ordem. Ou seja, os dispositivos, não apenas expressam, mas também definem, através dos discursos implícitos em sua configuração, as diversas formas de relação entre os sujeitos e o universo simbólico ali disponível (documentos, registros, informações, conhecimento). 
Desse modo, compreende-se que a mediação circunscreve um conjunto de práticas de intervenção e de interferência que mobiliza o dispositivo (no caso os ambientes de informação, em especial, a biblioteca), conferindo-lhe dinâmica informacional de caráter técnico (dinamiza os processos de atuação da biblioteca no que se refere as perspectivas implícitas), pedagógico e cultural (dinamiza os processos de atuação da biblioteca no que se refere as perspectivas explícitas) e político-institucional (dinamiza os processos de atuação da biblioteca no contexto gerencial e decisional).

Nessa perspectiva, Gomes e Santos (2011, p. 832), ao refletirem sobre a biblioteca na perspectiva da mediação consideram que:

[...] o ambiente físico da biblioteca já representa um importante elemento para o desenvolvimento dos usuários da informação, haja vista que o conjunto de elementos materiais da biblioteca tem um objetivo específico que é o de possibilitar e facilitar, de modo confortável, o acesso e uso da informação. Ao se observar o modo como esses objetos são articulados e disponibilizados, a maneira pela qual os profissionais da biblioteca realizam o atendimento, o modo como os usuários se comportam, as informações que são visualizadas nesse espaço, se verifica que todos esses elementos, entre outros, geram sentidos e transmitem significado para os sujeitos. Significados que podem ou não provocar nesses sujeitos um sentimento mais positivo em relação a esse ambiente. Caso seja positivo, esses sujeitos podem passar a considerar a biblioteca como um ambiente propício à construção de conhecimentos.

Partindo desse pressuposto, a biblioteca como ambiente de mediação informação, deve pensar os procedimentos necessários para o desenvolvimento e concepção do conceito de $\mathrm{MI}$ a partir das suas atividades gerenciais, programas e projetos e serviços de informação, reconhecendo-a como espaço de construção de significados para serem compartilhados através das práticas informacionais e culturais nela produzidos.

É nesse quadro que se verifica a importância de estudos da GC e da MI no âmbito das BTA's como forma de investigar a criação, o armazenamento e o compartilhamento de conhecimento e melhores práticas durante as atividades técnicas, pedagógicas e organizacionais que envolvem o desenvolvimento e atuação dessas bibliotecas no que se refere à dinâmica da informação nas instituições de ensino superior.

Nesse sentido, se vislumbra como necessária uma abordagem da GC nos processos de MI no ambiente das BTA's, pois a matéria-prima de sua atuação é a informação, que por sua vez é insumo para a construção de conhecimentos que objetivam atender às necessidades informacionais de determinada comunidade.

\section{O CONTRIBUTO DA GESTÃO DO CONHECIMENTO PARA OS PROCESSOS DE MEDIAÇÃO DA INFORMAÇÃO EM BIBLIOTECAS TÉCNICO-ACADÊMICAS}

Vimos até aqui uma sucinta amostra sobre a envergadura dos temas gestão do conhecimento e mediação da informação, bem como sua importância quando trabalhados no contexto das BTA's. Assim, apresentaremos algumas das contribuições que a GC pode oferecer aos processos de $\mathrm{Ml}$ através de ações ou práticas nesses ambientes.

Nos institutos federais, as BTA's são estruturadas para oferecer suporte a todas as atividades/ações/iniciativas ligadas ao ensino, pesquisa e extensão desde o ensino médio técnico/integrado à pós-graduação, objetivando a promoção de informação e conhecimento através da dinamização de seus serviços e produtos.

Perspectivas em Gestão \& Conhecimento, João Pessoa, v. 10, n. 3, p. 3-18, set./dez. 2020. 
Para o alcance desses objetivos, as BTA's têm seus ambientes organizacionais estruturados com base na gestão estratégica, processos informacionais, tecnologias e pessoas, elementos que as tornam organizações com base no conhecimento (ANGELONI, 2008), sendo o bibliotecário o responsável por planejar e executar através dos processos de $\mathrm{MI}$, de forma implícita e explícita, as ações de dinamização desses equipamentos.

A GC como prática gerencial vem a contribuir de forma efetiva nesse contexto quando age no sentido para que cada membro da biblioteca, através dos processos de Ml e suas multiatividades, compartilhe/externalize/ registre seu conhecimento aos demais membros subsidiando deste modo a criação de novos conhecimentos, bem como a inovação, agregando valor aos serviços e produtos disponibilizados que por sua vez serão novamente partícipes nos futuros processos de mediação.

O Quadro 2 revela possíveis contribuições da GC nos processos de MI nas BTA's:

Quadro 2 - Contribuições da gestão do conhecimento nos processos de mediação da informação em bibliotecas técnico-acadêmicas

\begin{tabular}{|c|c|}
\hline AÇÕES/PRÁTICAS & SERVIÇOS / PRODUTOS COM VALOR AGREGADO \\
\hline $\begin{array}{l}\text { Serviço de seleção e aquisição da } \\
\text { informação }\end{array}$ & $\begin{array}{l}\text { Comissão composta por bibliotecário, representante dos docentes e } \\
\text { representantes dos alunos, a fim de que os materiais a serem } \\
\text { comprados tenham usabilidade e relevância dentro da instituição } \\
\text { (registrar em manuais as políticas de desenvolvimento e aquisição de } \\
\text { coleções). }\end{array}$ \\
\hline $\begin{array}{l}\text { Serviço de tratamento da } \\
\text { informação (triagem do material } \\
\text { informacional, registro, } \\
\text { verificação, catalogação, } \\
\text { classificação) }\end{array}$ & $\begin{array}{l}\text { São ações que determinarão a facilidade com que os usuários irão } \\
\text { resgatar o registro de determinada obra através do sistema de } \\
\text { gerenciamento do acervo. Cabe ao bibliotecário utilizar esses } \\
\text { instrumentos com cuidado, pois por meio deles será possível inserir, } \\
\text { descrever e identificar o conteúdo temático dos materiais. Destaca- } \\
\text { se aqui a importância das políticas de indexação, catalogação e } \\
\text { classificação. }\end{array}$ \\
\hline Alerta informacional & $\begin{array}{l}\text { Através do perfil do usuário em banco de dados relacional, enviar e- } \\
\text { mail informando a chegada de materiais informacionais que } \\
\text { correspondam ao perfil de interesse do usuário (procurar manter o } \\
\text { banco de dados sempre atualizado). }\end{array}$ \\
\hline Lista de novas aquisições & $\begin{array}{l}\text { Informações no site ou no mural da instituição com as novas } \\
\text { aquisições da biblioteca. }\end{array}$ \\
\hline $\begin{array}{l}\text { Relação de websites no site da } \\
\text { biblioteca }\end{array}$ & $\begin{array}{l}\text { Viabilização da compilação dos sites relevantes, ou seja, das fontes } \\
\text { de informação específicas de cada área do conhecimento, devendo o } \\
\text { bibliotecário ficar atento à mudança constante dos endereços } \\
\text { existentes na web. }\end{array}$ \\
\hline Serviço de referência & $\begin{array}{l}\text { Levantamento de recursos informacionais e suporte para } \\
\text { normalização de trabalhos acadêmicos (disponibilizar em bases de } \\
\text { dados as melhores práticas conduzidas pelo setor). }\end{array}$ \\
\hline $\begin{array}{l}\text { Disseminação seletiva da } \\
\text { informação }\end{array}$ & $\begin{array}{l}\text { Divulgar informações: artigos, eventos, concursos etc., de acordo } \\
\text { com a área de atuação ou estudo do usuário. }\end{array}$ \\
\hline Agilidade do atendimento & $\begin{array}{l}\text { Envolve competência, habilidades técnicas e interpessoais dos } \\
\text { colaboradores no momento de resposta da demanda (registrar e } \\
\text { compartilhar as melhores). }\end{array}$ \\
\hline Flexibilidade & $\begin{array}{l}\text { Equipe com capacidade de mudar rapidamente a operação devido às } \\
\text { necessidades dos usuários. Sem ferir os padrões estruturantes: } \\
\text { normas internas ou hierárquicas (cultura organizacional de } \\
\text { aprendizagem é fundamental para essa ação). }\end{array}$ \\
\hline Condução de pesquisas & $\begin{array}{l}\text { Propiciar o acompanhamento e realizar diálogos com o usuário } \\
\text { (estratégico registrar as boas condutas de pesquisas como }\end{array}$ \\
\hline
\end{tabular}

Perspectivas em Gestão \& Conhecimento, João Pessoa, v. 10, n. 3, p. 3-18, set./dez. 2020. 


\begin{tabular}{|c|c|}
\hline & experiências para as futuras). \\
\hline Visitas orientadas & $\begin{array}{l}\text { Deve ser realizada com o propósito de instruir a comunidade técnico- } \\
\text { acadêmica sobre os procedimentos e requisitos necessários para } \\
\text { usufruir os serviços/ produtos que a biblioteca tem a oferecer } \\
\text { (importante registrar os feedbacks do público para o } \\
\text { aperfeiçoamento do serviço). }\end{array}$ \\
\hline Ações culturais & $\begin{array}{l}\text { Desenvolver eventos, palestras, exposições pontuais, a fim de tornar } \\
\text { a biblioteca um espaço de efervescência cultural, de formação social } \\
\text { e política. É de suma importâncias que as ações culturais sejam } \\
\text { capazes de agregar, no processo de construção das ações, a } \\
\text { comunidade de interna e externa, valorizando os saberes e a história } \\
\text { das comunidades, e construindo o sentindo de protagonismo social } \\
\text { nos envolvidos no processo. }\end{array}$ \\
\hline $\begin{array}{l}\text { Produtos de informação físico e } \\
\text { virtual }\end{array}$ & $\begin{array}{l}\text { Elaboração de manuais em formato presencial e principalmente } \\
\text { virtual sobre normalização documentária; } \\
\text { Elaboração manuais/guias/cartilhas sobre acesso a bases de dados } \\
\text { especializadas (para padronizações de procedimentos); } \\
\text { Elaboração de manuais/guias/cartilhas para acesso a e-book, } \\
\text { periódicos e anais de eventos; } \\
\text { Elaboração de manuais/guias/cartilhas } \\
\text { organização/preenchimento de currículos; } \\
\text { Elaboração de manuais/guias/cartilhas sobre o desenvolvimento de } \\
\text { trabalhos acadêmicos; } \\
\text { Orientação sobre a construção de projetos para concorrer a editais } \\
\text { internos (própria Instituição) e externos (órgãos de fomento públicos } \\
\text { e privados); } \\
\text { Construção de aplicativo incentivando acesso à informação científica } \\
\text { disponibilizada oficialmente pela biblioteca e dos aspectos científicos } \\
\text { em geral existentes nos ambientes virtuais; } \\
\text { Criação de repositório institucional para registro, preservação e } \\
\text { disseminação da produção científica docente, discente e técnico- } \\
\text { administrativa do Instituto Federal. }\end{array}$ \\
\hline $\begin{array}{l}\text { Ambiente Virtual de } \\
\text { Aprendizagem (AVA) }\end{array}$ & $\begin{array}{l}\text { Construção de uma plataforma virtual de aprendizagem integrada à } \\
\text { biblioteca onde seria possível disponibilizar diversos cursos de curta } \\
\text { duração relacionados às atividades acadêmicas, tais como: Como } \\
\text { elaborar artigos científicos; Plataforma Lattes: como criar e } \\
\text { preencher seu currículo; Normalização e formatação automática de } \\
\text { documentos acadêmicos; Normas da ABNT para documentos } \\
\text { acadêmicos; Introdução a metodologia científica; Estratégias de } \\
\text { busca na recuperação da informação em ambientes digitais/virtuais, } \\
\text { etc. Além dessas propostas, a plataforma poderia ser construída com } \\
\text { a comunidade, onde todos (as), poderiam colaborar propondo cursos } \\
\text { para a plataforma (servidores, alunos e comunidade externa), que } \\
\text { tenham interesse. Nessa perspectiva, podemos observar de forma } \\
\text { mais direta o potencial da biblioteca em alinhar as práticas de GC e } \\
\text { MI, ao possibilitar o compartilhamento dos conhecimentos da } \\
\text { comunidade em formato de cursos EAD. }\end{array}$ \\
\hline $\begin{array}{l}\text { Curadoria digital para serviços de } \\
\text { informação }\end{array}$ & $\begin{array}{l}\text { É necessário que o bibliotecário esteja atento aos processos e } \\
\text { avanços tecnológicos digitais e faça a diferença planejando e } \\
\text { implementando novas propostas de Serviços de Referência a partir } \\
\text { do processo de curadoria digital. Desenvolver serviços de informação } \\
\text { para a web para além das abordagens tradicionais dos sistemas de } \\
\text { organização do conhecimento. Aqui o bibliotecário necessita } \\
\text { compreender a importância de apropriação das novas TICs para }\end{array}$ \\
\hline
\end{tabular}

Perspectivas em Gestão \& Conhecimento, João Pessoa, v. 10, n. 3, p. 3-18, set./dez. 2020. 


\begin{tabular}{|l|l|}
\hline \multirow{5}{*}{ Serviços de informação utilitária } & $\begin{array}{l}\text { desempenhar de maneira plena o seu papel social, bem como sua } \\
\text { participação como agente transformador para o movimento da } \\
\text { Ciência Aberta. }\end{array}$ \\
\hline $\begin{array}{l}\text { Ações voltadas para o cotidiano da comunidade (saúde, política, } \\
\text { economia, cultura e lazer, educação, trabalho, meio ambiente, } \\
\text { tecnologia etc.). Um programa de informação utilitária permitiria a } \\
\text { construção coletiva de informações da biblioteca para e com a } \\
\text { comunidade. É uma importante estratégia para aproximar os } \\
\text { usuários das bibliotecas e fazê-los perceber que a biblioteca faz parte } \\
\text { do seu dia-a-dia. Para tanto, a biblioteca junto com a comunidade } \\
\text { poderia promover, palestras, debates, campanhas/intervenções, } \\
\text { elaboração de cartilhas/boletins informativos etc. }\end{array}$ \\
\hline $\begin{array}{l}\text { Treinamentos: sobre como utilizar os serviços e produtos da } \\
\text { biblioteca, inclui desenvolvimento para uso de ferramentas e visita } \\
\text { orientada ao espaço físico e virtual da biblioteca. } \\
\text { Capacitação: inclui curso de formação nas áreas de interesse da } \\
\text { comunidade e eventos como palestras, videoconferências, além de } \\
\text { cursos virtuais (a biblioteca poderia desenvolver sua própria } \\
\text { plataforma de Aprendizagem Virtual). Os programas de educação de } \\
\text { usuários ainda podem gerar novos projetos onde coloquem os } \\
\text { usuários como sujeitos multiplicadores, criando programas de } \\
\text { monitorias onde aqueles alunos que já realizaram cursos nos } \\
\text { programas de capacitação da biblioteca possam assumir o papel de } \\
\text { formador, ou mesmo propor novos cursos e atividades a partir de } \\
\text { suas competências e habilidades, que possam agregar e gerar novos } \\
\text { produtos, serviços de programas para a biblioteca. }\end{array}$ \\
\hline
\end{tabular}

Fonte: Adaptado de Santos e Massuqueto (2016) e Silva (2016)

Mediante o exposto no Quadro 2, observa-se que cada ação/prática pode ser desenvolvida em caráter particular, mas principalmente de maneira articulada e integrada. As ações planejadas de modo integrado fortalecem as relações entre a MI e a GC, ao reconhecer que os serviços técnicos e aqueles de cunho mais pedagógico são complementares para que a biblioteca exerça plenamente seu papel de ambiente informacional. Nessa perspectiva, cada ação/prática é fundamentalmente pensada/articulada como atividade gerencial e estruturada/executada como atividade mediacional compreendendo o caráter estratégico da relação GC-MI, possibilitando práticas consistentes que interfiram nas decisões de atuação da biblioteca e na construção da informação através da relação biblioteca-comunidade.

Partindo desse pensamento, compartilhamos do pensamento de Gomes (2014), que o processo de mediação da informação depende do nível de conscientização do mediador, ou seja, quando a mediação é consciente, a dialogia assegura o exercício da crítica e torna mais evidente as incompletudes e as lacunas que provocam a desestabilização dos conhecimentos já estabilizados no sujeito.

Portanto, vale salientar também sobre a importância do desenvolvimento dessas práticas de forma integrada aos conceitos de GC, a partir de uma perspectiva dialógica, estética, formativa, ética e política da mediação da informação, proposta por Gomes (2014, 2019), como descrita em sequência:

a) Práticas de mediação da informação a partir de uma perspectiva dialógica: compreende que o usuário é sujeito ativo do processo de construção da informação, ou seja, as práticas aqui não são construídas para o usuário, mas com os usuários. Aqui, A ação mediadora, compreendida como essencialmente pautada na dialogia que possibilita o encontro e a manifestação das subjetividades que emanam da 
interlocução inter e intrassubjetiva, garantindo o acolhimento, a escuta, a observação, o diálogo, o acesso a diversidade de ideias e a liberdade de pensamento, inibindo a censura e o preconceito (GOMES, 2014).

b) Práticas de mediação da informação a partir de uma perspectiva estética: sentindose parte do processo de construção dos significados e ações de informação, os usuários se percebem, se encontram, se identificam e se emocionam com as práticas a partir das suas percepções de mundo, suas histórias, suas experiências. Dessa forma, a dimensão estética consegue superar as configurações meramente físicas do ambiente físico da biblioteca, pois ela conquista um caráter de semiótico da mediação, "dependente das diversas linguagens e da consciência de que todos os envolvidos na ação são interlocutores e protagonistas do processo" (GOMES, 2014, p.56).

c) Práticas de mediação da informação a partir de uma perspectiva formativa: quando as práticas de compartilhamento, de cooperação, de abertura ao diálogo e diferentes expressões de pensamento, geram criatividade, crítica, autonomia no processo de construção das ações, as práticas ganham seu sentido formativo. Ao transitar por essas "vias" com conforto e confiabilidade os sujeitos envolvidos sentem-se acolhidos como participantes ativos, como protagonistas da informação e, consequentemente, sentem o prazer dessa experiência e do aprendizado. Este caráter, alinha as dimensões estéticas e formativas, mas que só são possíveis de realizar quando o nível de conscientização do mediador permite a escuta e observação sensível das emoções e sentimentos gerados pelo processo de $\mathrm{MI}$, sendo o momento de também pensar sobre a dimensão ética da mediação (GOMES, 2014);

d) Práticas de mediação da informação a partir de uma perspectiva ética: compreende que a MI implica pensar sobre o protagonismo do usuário da informação, uma vez que o processo de apropriação da informação não deve ser decidido de forma isolada, arbitrária ou manipulada, mas sim deve promover em suas ações processos de interferência que promovam subsídios interativos, respeitosos e profícuos, permitindo ao usuário desenvolver suas próprias percepções em torno das informações de acordo com sua percepção de mundo e suas experiências e vivências cotidianas, inibindo a censura e o preconceito (GOMES, 2014);

e ) Práticas de mediação da informação a partir de uma perspectiva política: a MI se desenvolvida com consciência, atinge sua dimensão política, isto porque, a dimensão política é capaz de integrar todas as outras, pois existe na sua essencial a compreensão que a atividade de mediar está ligada ao modo de vida das pessoas, a sua cultura, suas crenças, sua história e seu papel no mundo. Este seria a perspectivas mais complexas, pois demanda uma conscientização por parte do bibliotecário e da comunidade em geral, de pensar como podemos construir, em comunidade, processos de construção e compartilhamento de informação humanizadores e emancipadores. (GOMES, 2019).

Outra questão fundamental para os processos de MI e GC destacados no quadro foi o uso intenso das tecnologias digitais, pois mediante as necessidades da sociedade contemporânea, considera-se que tecnologias digitais favorece as contribuições da GC para a $\mathrm{MI}$, visto que muitas ações/práticas envolvem a dinâmica do aparato físico e virtual/digital.

Ainda, destacando a dimensão formativa da $\mathrm{MI}$, em ações/práticas como: educação de usuários, ações culturais, AVA, observa-se, de forma mais direta, as relações entre GC e MI, pois são atividades agregadoras de novas informações e potencialmente geradoras de criatividade e novos conhecimentos, pois possuem potencial de compartilhamento de conhecimento e protagonismo social. Nessa perspectiva, comunga-se do pensamento de Gomes (2019, p. 15) quando afirma que informação é conhecimento em estado de compartilhamento, isto é, "qualidade de ação e de instância do colocar em comum o quê se 
sabe, sente e pensa, o coloca a informação na condição daquilo que potencialmente pode mover a tomada de posição e, ao mesmo tempo, como resultante de uma posição anterior de compartilhamento".

Importante frisar que as ações e práticas demonstradas são apenas algumas das possíveis de serem realizadas pelas bibliotecas dos institutos federais, mas que em todas é perceptível a contribuição valiosa da GC como uma ferramenta de apoio imprescindível para agregação de valor nas dinâmicas dessas atividades, tendo como função também promover a geração de novos conhecimentos nas próprias BTA's.

\section{CONSIDERAÇÕES FINAIS}

O presente estudo mostrou algumas percepções de abordagem aproximativa entre os temas da GC e MI, além de revelar de modo especial a pertinência de trabalhá-los conjuntamente nos ambientes de técnico-acadêmicos das bibliotecas dos institutos federais.

As ações e práticas do Quadro 2, expostas na seção anterior, são algumas das possibilidades apresentadas do caráter estratégico e contributivo da GC nos processos de $\mathrm{MI}$ no contexto das BTA's, auxiliando na promoção de novas dinâmicas mediacionais, a medida em que trabalha: - a difusão do conhecimento através da criação dos próprios recursos informacionais da biblioteca; - a aplicação do conhecimento por meio da promoção de serviços que facilitam a aquisição de conhecimento tanto a bibliotecários quanto aos usuários; e - os recursos humanos através de investimentos na formação de capital intelectual para revitalizar o ambiente da biblioteca.

Entende-se que pelo caráter inesgotável das discussões sobre GC e Ml, como também de suas contribuições para a Ciência da Informação, este estudo não deve estabelecer conclusões definitivas, mas indicar a possibilidade de novas discussões sobre os temas GC e MI.

Assim, destacamos a importância das reflexões como estímulo para elaboração de estudos futuros sobre GC e MI em bibliotecas no geral e BTA's em particular como, por exemplo: contribuições da GC para MI através do uso de tecnologias; contribuições da GC para MI através dos serviços de informação; GC como fenômeno de estímulo à educação de usuários através do incentivo ao ensino, pesquisa e extensão; Contribuições da MI para GC no âmbito do protagonismo social, entre outros.

Como resultado, podemos observar que a GC pode contribuir de maneira expressiva e relevante nos processos de MI nas BTA's, implicitamente ou explicitamente, através da dinâmica de suas ações e práticas elevando a qualidade de seus serviços e produtos, estimulando a inovação nesses ambientes.

\section{REFERÊNCIAS}

ALMEIDA JÚNIOR. O. F. Mediação da informação e múltiplas linguagens. Pesquisa Brasileira em Ciência da Informação, Brasília, v.2, n.1, p.89-103, jan./dez. 2009.

ANGELONI, M. T. Organizações do conhecimento: infra-estrutura, pessoas e tecnologias. 2. ed. rev. e ampl. São Paulo: Saraiva, 2008.

BICHERI, A. L. A. D. O. A mediação do bibliotecário na pesquisa escolar face a crescente virtualização da informação. Marília, 2008. 198f. Dissertação (Mestrado em Ciência da Informação) - Universidade Estadual Paulista, 2008. Disponível em: https://goo.gl/T5y2CP. Acesso em: 09 maio 2020.

Perspectivas em Gestão \& Conhecimento, João Pessoa, v. 10, n. 3, p. 3-18, set./dez. 2020. 
CASTRO, G. de. Gestão do conhecimento em bibliotecas universitárias: um instrumento de diagnóstico. 2005. 161 f. Dissertação (Mestrado em Ciência da Informação) - Universidade Federal de Santa Catarina, Florianópolis, 2005.

CHOO, C. W. A organização do conhecimento: como as organizações usam a informação para criar significado, construir conhecimento e tomar decisões. São Paulo: SENAC, 2003.

DALKIR, K. Knowledge sharing networks. IN: CIANCONI, R. B.; CORDEIRO, R. I. N.; ALMEIDA, C. H. M. (Orgs.). Gestão do conhecimento, da informação e de documentos em contextos informacionais. Niterói, RJ: EDUFF, 2013. p. 13-26.

DAVENPORT, T.; PRUSAK, L. Conhecimento empresarial: como as organizações gerenciam o seu capital intellectual. Rio de Janeiro: Campus, 1998.

DUARTE, E. N. Análise da produção científica em gestão do conhecimento: estratégias metodológicas e estratégias organizacionais. 2003. Tese de Doutorado em Administração, Universidade Federal da Paraíba, 2003.

DUARTE, E. N.; FEITOZA, R. A. de B.; MONTEIRO, M. F.; LIMA, A. R. P. de. Conteúdos emergentes da gestão da informação e do conhecimento nos cursos de pós-graduação em Ciência da Informação no Brasil. Perspectivas em Gestão \& Conhecimento, v. 10, n. Especial, p. 176-200, 24 mar. 2020.

FERREIRA, L. E.; ALMEIDA JUNIOR, O. F. A mediação da informação no âmbito da arquivística. Perspectiva em Ciência da informação, Belo Horizonte, v. 18, n. 1, p. 158-167, jan./mar. 2013.

GOMES, H. F. A mediação da informação, comunicação e educação na construção do conhecimento. DataGramaZero, Rio de Janeiro, v. 9, n. 1, 2008. Disponível em: https://repositorio.ufba.br/ri/handle/ri/3041. Acesso em: 09 maio 2020.

GOMES, H. F.; SANTOS, R. R. A mediação da informação e bibliotecas universitárias: a situação do uso dos dispositivos de comunicação da web social. In: ENCONTRO NACIONAL DE PESQUISA EM CIÊNCIA DA INFORMAÇÃO, 12., Anais [...] Brasília, DF, 2011. p. 830-846.

GOMES, H. F. A dimensão dialógica, estética, formativa e ética da mediação da informação. Inf. Inf., Londrina, v. 19, n. 2, p. $46-59$, maio/ago. 2014.

GOMES, H. F. Protagonismo social e mediação da informação. LOGEION: Filosofia da informação, Rio de Janeiro, v. 5 n. 2, p.10-21, mar./ago. 2019.

MAIA, C. Casa de ferreiro, espeto de pau - a gestão do conhecimento em empresas produtoras de conhecimento. In: TERRA, J. C. C. Gestão do conhecimento e e-learning na prática. Rio de Janeiro: Elsevier, 2003. p. 4-18.

MAPONYA, P. M. Knowledge management practices in Academic libraries: a case study of the University of Natal, Pietermaritzburg Libraries, 2004. Disponível em: http://mapule276883.pbworks.com/f/Knowledge+management+practices+in+academic+librar ies.pdf. Acesso em: 09 maio 2020. 
McMANUS, D.; LOUGHBRIDGE, B. Corporate information, institutional culture and knowledge management: a UK university libray perspective. New Libray World, v. 103, n. 1180, p. 320327, 2002.

NONAKA, I.; TAKEUCHI, H. Gestão do conhecimento. Porto Alegre: Bookman, 2008.

PIERUCCINI, I. A ordem informacional dialógica: estudos sobre a busca de informação em educação. São Paulo: USP, 2004, 232f. Tese (doutorado) - Universidade de São Paulo/ Escola de Comunicações e Artes, Programa de pós-graduação em Ciências da Comunicação, 2004.

ROSTIROLLA, G. Gestão do conhecimento no serviço de referência em bibliotecas universitárias: uma análise com foco no processo de referência. Dissertação (Mestrado em Ciência da Informação) - Programa de Pós-graduação em Ciência da Informação da Universidade Federal de Santa Catarina, Santa Catarina, 2006.

SANTOS, C. D.; VALENTIM, M. L. P. As interconexões entre a gestão da informação e a gestão do conhecimento para o gerenciamento dos fluxos informacionais. Perspectivas em Gestão \& Conhecimento, v. 4, n. 2, p. 19-33, 2 ago. 2014.

SANTOS, N. K. de C.; MASSUQUETO, K. A gestão do conhecimento como recurso valorativo nas ações das bibliotecas universitárias. Revista Interdisciplinar Científica Aplicada, Blumenau, v.10, n.1, p. 01-14, TRI I 2016.

SBGC - SOCIEDADE BRASILEIRA DE GESTÃO DO CONHECIMENTO. Conceito-ensaio de gestão do conhecimento. 2013. Disponível em: http://www.sbgc.org.br/blog/conceito-ensaio-de-gestaodo-conhecimento. Acesso em: 11 maio 2020.

SILVA, J. L. C. Percepções conceituais sobre mediação da informação. Revista de Ciência da Informação e Documentação, Ribeirão Preto, v. 6, n. 1, p. 93-108, mar./ago. 2015.

SILVA, J. L. C.; SILVA, A. S. R. A mediação da informação como prática pedagógica no contexto da biblioteca escolar: algumas considerações. Bibl. Esc. em Rev., Ribeirão Preto, v. 1, n. 2, p. 130, 2012.

SILVA, J. C. Como a biblioteca universitária pode contribuir para as práticas de pesquisa? 2016. Disponível em: http://www.ofaj.com.br/colunas conteudo.php?cod=1022. Acessado em: 11 maio 2020.

SOUSA, C. H. da S. Gestão do conhecimento na Rede de Bibliotecas do Instituto Federal de Educação, Ciência e Tecnologia do Ceará: uma proposta de implementação. 2017. $114 \mathrm{f}$. Dissertação (Mestrado) Mestrado Profissional em Biblioteconomia - Universidade Federal do Cariri, Juazeiro do Norte-CE, $2017 . \quad$ Disponível em: http://biblioteca.ifce.edu.br/index.asp?codigo sophia=69184. Acesso em: 09 mar. 2020.

SOUSA, P. de T. C. de. O capital social estratégico como recurso para a gestão da informação e do conhecimento no processo eleitoral brasileiro. 2009. $227 \mathrm{f}$. Tese (Doutorado em Ciência da Informação) - Universidade de Brasília, Brasília, 2009. 
TEIXEIRA, C. da C. A cultura organizacional e informacional em ambiente técnico-acadêmico. 2015. 161 f. Dissertação (Mestrado em Ciência da Informação) - Universidade Federal Fluminense, Niterói, 2015.

THE INTERNATIONAL FEDERATION OF LIBRARY ASSOCIATIONS AND INSTITUTIONS - IFLA. 2019. Disponível em: http://www.ifla.org/en/about-the-km-section. Acesso em: 20 maio 2020.

VALENTIM, M. L. P. Gestão da informação e gestão do conhecimento em ambientes organizacionais: conceitos e compreensões. Tendências da Pesquisa Brasileira em Ciência da Informação, Brasília, v.1, n.1, p. 1-16, 2008. Disponível em: https://brapci.inf.br/index.php/res/v/119521. Acesso em: 07 mar. 2020. 